

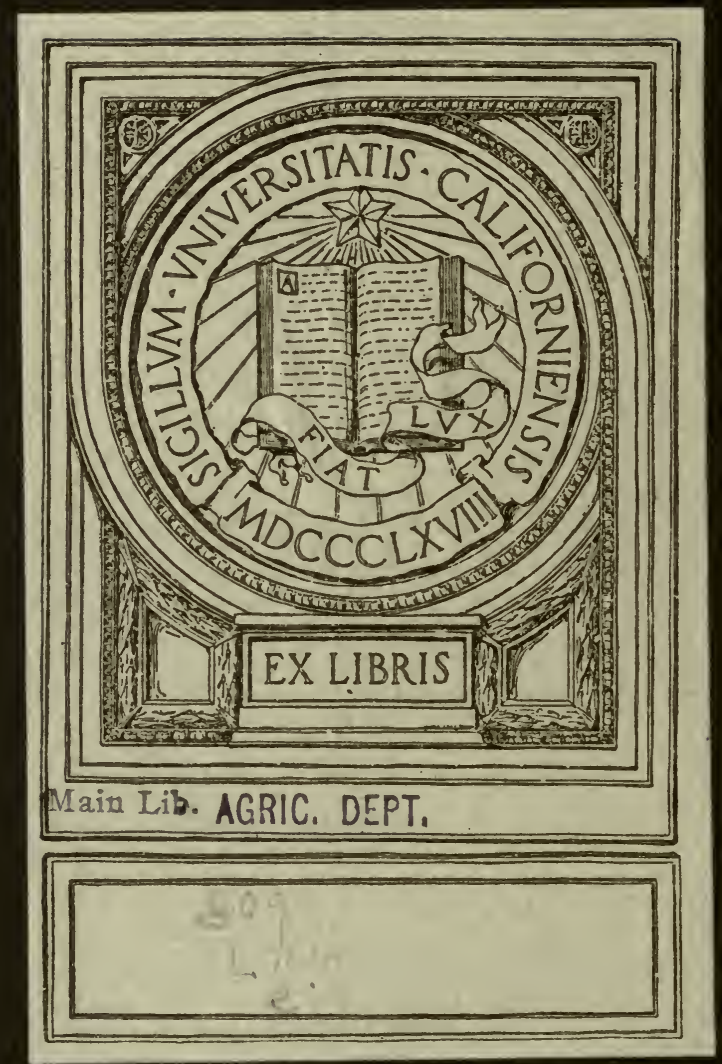




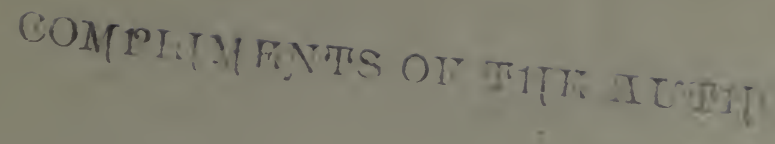

The Effect of Ignition on the Solubility of Soil Phosphate.
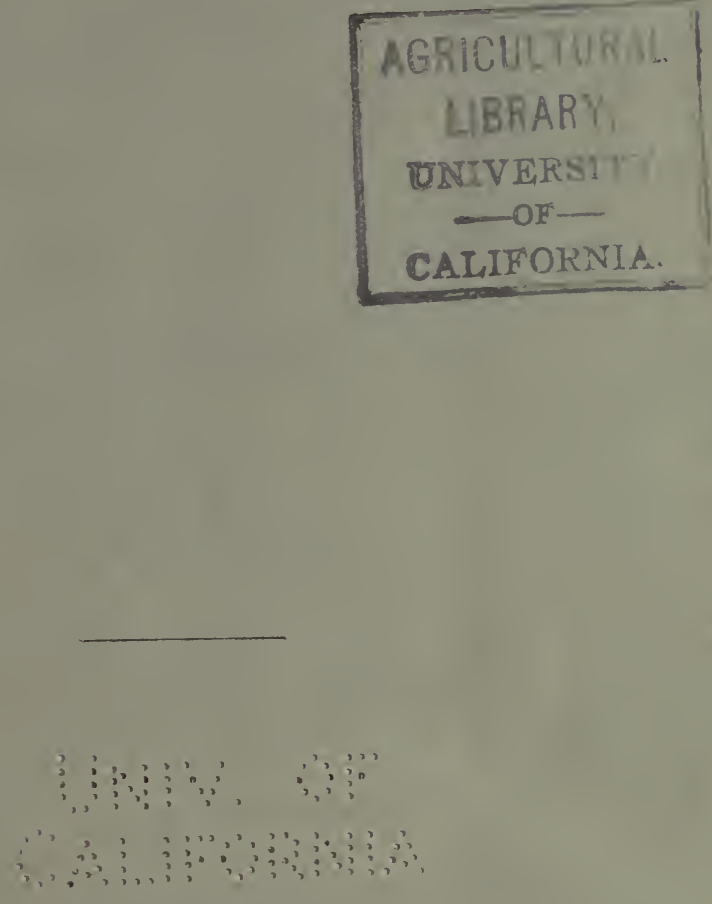

By Chas. B. Lipman. 
$3^{2}$

Maiu I.ib

Agric. Dept

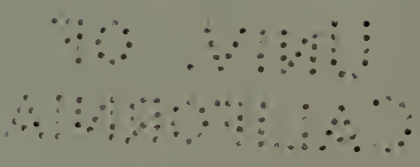


[Reprinted from the Journal of Industrial and Engineering Che mistry,
Vol. 4. No. 9. September, 1912].
CAIIFORNIA.

\section{THE EFFECT OF IGNITION ON THE SOLUBILITY OF SOIL PHOSPHATES.}

By Chas. B. Lipman.

Received July $31,1912$.

In common with other soil investigators, the writer has taken occasion to point out recently the dangers involved in applying data obtained with solution cultures of plants to soil problems with the same plants. Time and again results have been obtained in solution cultures of both plants and bacteria which when compared with tests of the same organisms on soils, both sterile and unsterile, were found to be widely divergent and discordant. I have also found the same to be true regarding the purely chemical changes of the same materials in minerals and in soils as brought about by the laboratory treatment involved in their quantitative determination. My remarks apply particularly to the quantitative determinations of phosphates in soil; I employ for this paper the same title that Fraps ${ }^{x}$ used for his recently, to call attention to the differences effected in the degree of solubility of phosphates in phosphate minerals and in soils, by ignition. In the work just cited, Fraps has shown that the ignition of phosphate minerals, including wavellite, dufrenite and variscite, for ro minutes at a low red heat increased about ro times the solubility of the phosphoric acid contained in them in fifth normal nitric acid and rendered it almost completely soluble in I 2 per cent. hydrochloric acid. From these results he concludes that the method for determining phosphoric acid in soils as used by him is not suited to distinguish between the organic and the inorganic phosphorus in soils, since the inorganic phosphates are made more soluble through ignition.

We are not concerned in this paper with the latter conclusion-of Fraps as regards the distinction between the organic and inorganic phosphorus of the soil. Having frequently noted, however, in our analytical work on soils that the very opposite effect to that above quoted is accomplished by ignition of soils before determining the phosphoric acid, it was deemed desirable to make some systematic tests with reference to the matter, and determine, if possible, the cause

1 This Journal, 3, 335. 
of the different effect of ignition on the solubility of phosphates in minerals and in soils, if such a different effect was definitely shown to exist. Accordingly five different soils were selected, each sifted through a $0.5 \mathrm{~mm}$. sieve and prepared for analysis for phosphoric acid. The soils were as follows:

No. I. A very rich, black, fine silty loam, rich in phosphoric acid and humus, from Arroyo Grande, San Luis Obispo County, California.

No. 2. A fine sandy soil with a good supply of phosphoric acid, but poor in humus, from Escondido, San Diego County, California.

No. 3. A very heavy black, clay adobe soil with sufficient phosphoric acid for fair crop production, from West Berkeley, Alameda County, California.

No. 4. A sandy loam with a fairly good humus and phosphoric acid content from South San Francisco, California.

No. 5. A light sandy loam, of fairly good humus content and phosphoric acid, from Anaheim, Orange County, California.

The analysis was carried out as follows: Four grams of soil were placed in a porcelain cup and digested with concentrated nitric acid for two days on the steam bath. Two saniples of each soil were ignited for twenty minutes at a low red heat in a platinum dish and two others of each soil were placed in the cups without ignition. The greatest caution was exercised to prevent loss by dusting in the process of ignition and in the transfer from platinum to digestion cup. After the period of digestion, the soil cups were placed on the sand bath and evaporated to dryness to dehydrate the silica, after which more acid and a little distilled water were added and the cups were replaced on the steam bath for four hours. The solutions were then carefully filtered and the soil residue washed on the filter. The filtrate was warmed to a temperature of $65^{\circ}$ to $70^{\circ} \mathrm{C}$. and the phosphoric acid precipitated with ammonium molybdate. The precipitate and solution were allowed to stand at $65^{\circ}$ to $70^{\circ} \mathrm{C}$. for about four hours, then filtered and the precipitate washed with a solution of ammonium nitrate. After this it was dissolved out with ammonia, and precipitated with magnesia mixture, then allowed to stand over night; filtered the next morning and washed with distilled water containing a little ammonia. The precipitate and filter were then dried, ignited, weighed and the phosphoric acid determined 
in the usual way. The percentages given represent averages of closely agreeing duplicates for each soil both ignited and unignited.

\begin{tabular}{cccccc}
\multicolumn{7}{c}{ Table I. } & Percentages & $\mathrm{P}_{2} \mathrm{O}_{5}$. \\
Soil No. & 1 & 2 & 3 & 4 & 5 \\
Ignited.................. & 0.410 & 0.150 & 0.090 & 0.167 & 0.151 \\
Not ignited............ & 0.460 & 0.250 & 0.130 & 0.191 & 0.190
\end{tabular}

The data given in Table I leave no room for doubt as to the effect of ignition on soil phosphates as existing in various soils. In most cases the loss in percentage is not very great, but it is always definite and in some cases, as in soil No. 2, it is quite marked. In practically all cases the duplicates agreed within one hundredth of a percent. We obtain therefore the very reverse effect of ignition on the soil phosphates as existing in the soil, from that obtained by Fraps on mineral phosphates as existing in minerals. In brief, ignition of soil appears to decrease appreciably and definitely the solubility of its phosphates whether they be largely inorganic or organic. The large variety of soils employed would seem further to strengthen the evidence, in that they doubtless contained largely varying proportions of inorganic and organic phosphates and a large variety of phosphate bearing minerals.

Just why these important differences exist in the effects of ignition on phosphates in minerals and in soils is an explanation that is not as easily found as the facts which obtain in the case. It would appear to be clear that the increased solubility of the phosphoric acid in minerals like wavellite, variscite and others tested by Fraps might be accomplished through the mechanical changes induced by the heat in the mineral employed. We know for example that heating of sand will disintegrate its grains and thus produce more surface. It is altogether likely that the same happens when a phosphate mineral is ignited and the result is the production of a larger surface for the nitric acid to act upon, hence an increase in solubility of phosphoric acid in the ignited over the unignited mineral. On the other hand, in a complex material like the soil, which contains besides many kinds of mineral and rock particles in different stages of disintegration, very considerable quantities of organic matter, both decaying and in living form, and the minerals and salts in different degrees hydrated, it is probable that the mineral particles would be protected from disintegration by 
heat so long as the water of hydration and the organic matter still remained in the soil; therefore no additional surface would be exposed to the action of the acid and besides, the dehydration of the organic, as well as inorganic phosphates, would seem to make them less soluble. Indeed I have data to show that dehydration without ignition also decreases the solubility of the soil phosphates. This explanation is offered by the writer for the facts noted, merely as a suggestion as to the phenomena probably occurring when mineral phosphates and soils are heated, as regards their phosphate content. It is hoped that an explanation or further suggestions will be forthcoming from my colleagues. This brief paper is offered merely as a partial report on one phase of the subject of the determination of phosphoric acid in soils, the whole of which is now being studied in our laboratory. Other interesting data besides that mentioned has already been obtained which we hope to include in another paper in which the whole subject will be treated more completely.

SoIls Research Laboratory, UNIVERSiTY OF CALIFoRNiA, Berkeley. 
THIS BOOK IS DUE ON THE LAST DATE STAMPED BELOW

AN INITIAL FINE OF 25 CENTS WILL BE ASSESSED FOR FAILURE TO RETURN THIS BOOK ON THE DATE DUE. THE PENALTY WILL INCREASE TO 50 CENTS ON THE FOURTH DAY AND TO $\$ 1.00$ ON THE SEVENTH DAY OVERDUE.

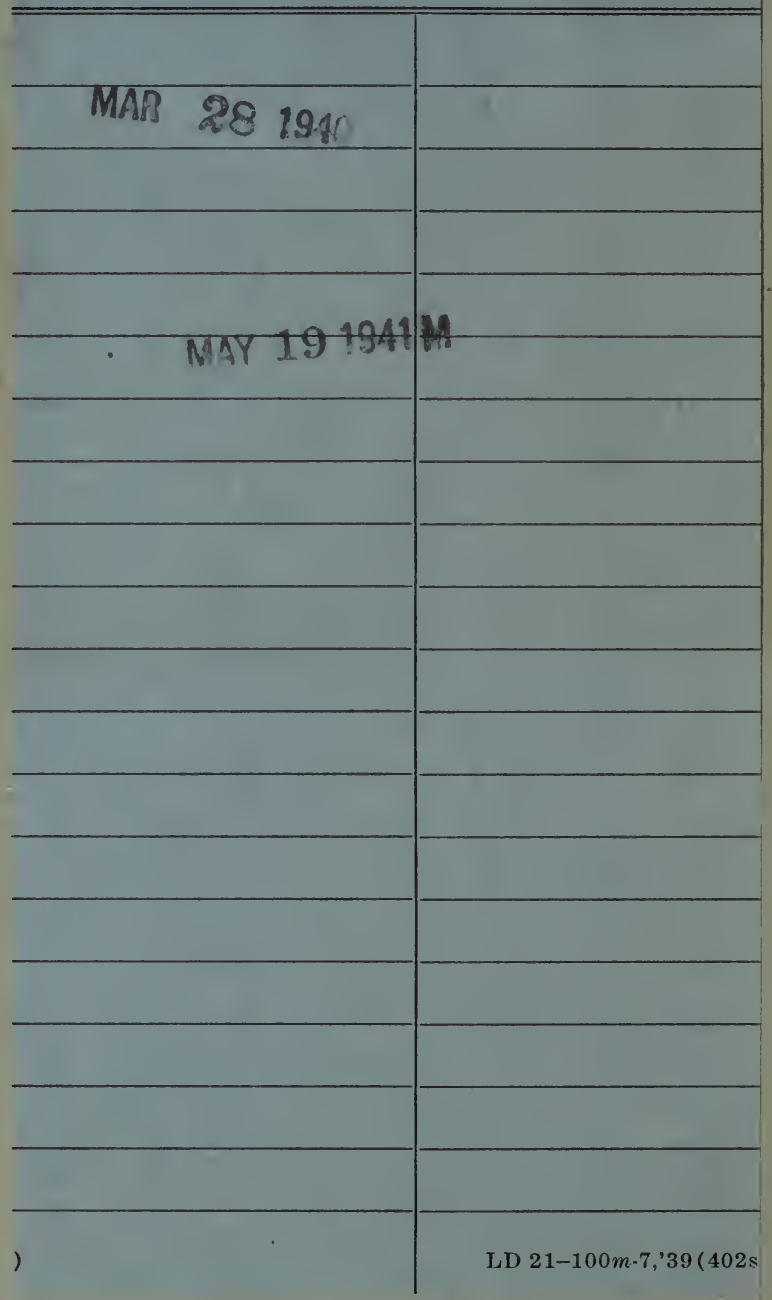


Gaylord Bros.

Makers

Syracuse, N. Y.

PAT. JAN. 21, 1908

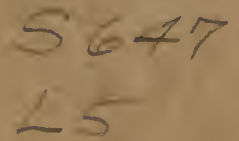

UNIVERSITY OF CALIFORNIA LIBRARY 


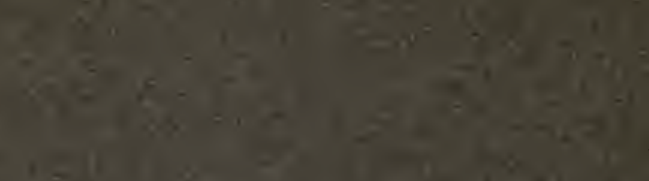

in $x^{2}+x^{2}-3$

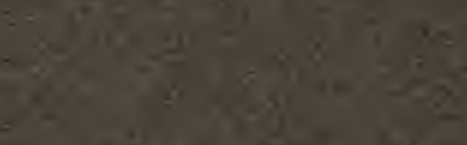

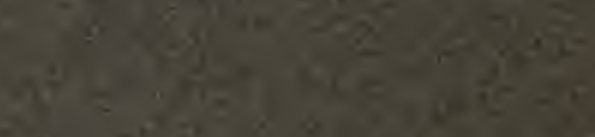

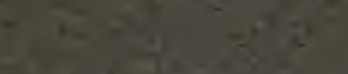

